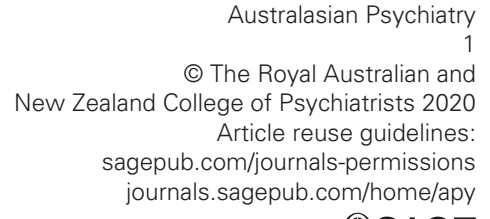

@SAGE

\section{Stepped mental health care model leading Australia astray}

Australia is facing a major transformation of its mental health system. Like any highly complex reform, selecting an appropriate change framework is critical. ${ }^{1}$

The Australian Government chose the 'stepped care' framework to guide mental health planning, promising people 'varying levels of primary care treatment and support depending on their level of need as determined by a health professional, whether that be 'at risk', mild, moderate or severe/ complex' [https://bit.ly/2OW9NrX].

There is evidence this framework may not be appropriate, even for common disorders. ${ }^{2}$ Stepped care is typically applied to specific therapies, like the UK's Improving Access to Psychological Therapies (IAPT). There, the model was implemented with coordinated tiers of care, from guided selfhelp, to low, then higher intensity and professional face-to-face care. ${ }^{3}$ Patient progress was systematically monitored.

Australian implementation of stepped care has taken this intervention-specific approach and applied it to the entire mental health system. Medicare's Better Access Program was not designed with clearly differentiated tiers of care or systematic monitoring of patient progress. It is not clear what a person should do next, if they still need assistance after Better Access. There are no steps.

Stepped care, as distinct from 'staged care', ${ }^{4}$ fails to meet the needs of people with more complex or persistent illness. No clear steps for people discharged from state public mental health services exist.

This misunderstanding highlights fundamental confusion between 'interventions' such as psychotherapy and drug prescription, versus 'services' such as a GP clinic or emergency department. ${ }^{5}$ Interventions are actions aimed at improving health. Services are structures providing care. Interventions occur in services. Services are inputs, while interventions are the throughputs.

Interventions provided as part of services in other countries frequently manifest in Australia as entirely new services! For example, interventions designed to coordinate complex care in Finland become Partners in Recovery here. In response to the onesize-fits-all Better Access Program, we add more services rather than develop multidisciplinary care.

An unintended consequence of stepped care may be further fragmentation of a system in crisis. A sophisticated, evidence-informed framework is urgently needed.

\section{ORCID iD}

Sebastian Rosenberg 3374-8694

\section{References}

1. Sturmberg JP, O'Halloran D, Colagiuri R, et al. Health care frames - from Virchow to Obama and beyond: the changing frames in health care and their implications for patient care. J Eval Clin Pract 2014; 20: 1036-1044.

2. van Straten A, Hill J, Richards DA, et al. Stepped care treatment delivery for depression: a systematic review and meta-analysis. Psychol Med 2015; 45: 231-246.

3. Gyani S, Shafran R, Layard T, et al. Enhancing recovery rates: lessons from year one of IAPT. Behav Res Ther 2013; 51: 597-606.

4. Cross SP, Hermens DF, Scott J, et al. Differential impact of current diagnosis and clinical stage on attendance at a youth mental health service. Early Interv Psychiatry 2017; 11: 255-262.

5. Castelpietra G, Salvador-Carulla L, Almborg AH, et al. Working draft: classifications of interventions in mental health care. An expert review. Eur J Psychiat 2017; 31: 127-144.

\section{Sebastian Rosenberg Sydney, NSW}

Luis Salvador-Carulla Centre for Mental Health

Research, Research School of Population Health, ANU College of Health and Medicine, Australian National University, Australia

Ian Hickie Sydney, NSW

John Mendoza Sydney, NSW

DOI: $10.1177 / 1039856220928858$ 